\title{
Effects of leachates from UV-weathered microplastic on the microalgae Scenedesmus vacuolatus
}

\author{
Christoph D. Rummel ${ }^{1}$ (D) Hannah Schäfer ${ }^{1} \cdot$ Annika Jahnke $^{2,3}$ (D) Hans Peter H. Arp ${ }^{4,5}$ (D) \\ Mechthild Schmitt-Jansen ${ }^{1}$ (1)
}

Received: 27 July 2021 / Revised: 20 October 2021 / Accepted: 19 November 2021 /Published online: 22 December 2021

(c) Springer-Verlag GmbH Germany, part of Springer Nature 2021

\begin{abstract}
Plastics undergo successive fragmentation and chemical leaching steps in the environment due to weathering processes such as photo-oxidation. Here, we report the effects of leachates from UV-irradiated microplastics towards the chlorophyte Scenedesmus vacuolatus. The microplastics tested were derived from an additive-containing electronic waste (EW) and a computer keyboard (KB) as well as commercial virgin polymers with low additive content, including polyethylene (PE), polyethylene terephthalate (PET), polypropylene (PP), and polystyrene (PS). Whereas leachates from additive-containing EW and KB induced severe effects, the leachates from virgin PET, PP, and PS did not show substantial adverse effects in our autotrophic test system. Leachates from PE reduced algae biomass, cell growth, and photosynthetic activity. Experimental data were consistent with predicted effect concentrations based on the ionization-corrected liposome/water distribution ratios $\left(D_{\text {lip/w }}\right)$ of polymer degradation products of PE (mono- and dicarboxylic acids), indicating that leachates from weathering $\mathrm{PE}$ were mainly baseline toxic. This study provides insight into algae toxicity elicited by leachates from UV-weathered microplastics of different origin, complementing the current particle- vs. chemical-focused research towards the toxicity of plastics and their leachates.
\end{abstract}

Keywords Microplastic $\cdot$ Leachates $\cdot$ Microalgae $\cdot$ Artificial weathering $\cdot$ Mode of toxic action $\cdot$ Electronic waste

\section{Introduction}

Interactions between plastic debris and biota have been reported for diverse taxa at different trophic levels [1]. In most ecotoxicological studies, this interaction focuses on effects from the ingestion or uptake of particles into the

Mechthild Schmitt-Jansen

mechthild.schmitt@ufz.de

1 Department of Bioanalytical Ecotoxicology, Helmholtz Centre for Environmental Research - UFZ, Permoserstr. 15, 04318 Leipzig, Germany

2 Department of Ecological Chemistry, Helmholtz Centre for Environmental Research - UFZ, Permoserstr. 15, 04318 Leipzig, Germany

3 Institute for Environmental Research, RWTH Aachen University, Worringerweg 1, 52074 Aachen, Germany

4 Norwegian Geotechnical Institute (NGI), Ullevål Stadion, P.O. Box 3930, 0806 Oslo, Norway

5 Department of Chemistry, Norwegian University of Science and Technology (NTNU), 7491 Trondheim, Norway test organisms. As globally distributed primary producers, microalgae have a high potential to interact with microplastics [2]. Adverse effects of microplastics towards microalgae may either stem directly from the physical presence of particles or by the secondary effects from leaching chemicals [3, 4]; however, these are difficult to distinguish due to their frequent co-occurrence. The first process may lead to particle adsorption, aggregation, loss of membrane integrity, or shading effects as discussed in previous studies $[2,5,6]$. In contrast, the second process of indirect effects induced by chemicals leaching from microplastics has gained little attention for microalgae so far, despite many algae being able to colonize on plastic surfaces $[7,8]$. The few studies that have considered leachates have confirmed the expected adverse effects by additive leaching $[9,10]$. The presence, release, and adverse effects of common plastic additives has been reported for a variety of polymer materials [11-13], yet it remains unclear whether toxicity of leachates is driven by additives, polymer residuals such as mono- or oligomers, or degradation products after weathering. 
The electronic waste microplastic (EW) herein was derived from an e-waste recycling/sorting facility and was previously reported to contain flame retardants, bisphenol A, polychlorinated biphenyls and antimony [14-16, 19]. Also included was microplastic generated from a key board (KB), which was also expected to contain chemical mixtures of additives, based on detectable effects of KB leachates in reporter gene assays [17]. Effects of leachate waters of these two sample types were compared to the leachate effects of comparatively additive-free pre-production polymer pellets that mainly contained polymer residuals and degradation products of polymers as a result of artificial weathering. Our previous research demonstrated that effects of plastic leachates on a cellular level may be induced by plastic degradation products solely, i.e., largely excluding effects of intentionally added plastic additives that may leach from the test material [17]. In Rummel et al. [17], we described the induction of cellular stress responses such as oxidative stress by plastic leachates from raw polymer pellets. Furthermore, adverse effects were elevated when leaching was conducted under strong UV light treatment that caused photo-oxidation of the polymers [17]. To further investigate the ecotoxicological relevance of these plastic leachates, in vivo, in this study, we test the potency of these leachates to induce adverse effects towards ecologically important low-trophic level representatives: microalgae. Following the OECD No. 201 test guideline [18], we addressed potential impairment of algal growth and a key physiological process, namely photosynthesis, in one test assay. Microalgae were chosen as suitable test organisms since we could ensure the test accuracy of cell-based tools but with increased biological complexity in comparison to our previously used test systems [17] by using a population-based test. Furthermore, the test system offers options to assess specific effects like the inhibition of photosynthesis and therefore to address a specific potential mode of action (MoA) of toxicants. Microalgae are representative primary producers that provide important ecosystem functions.

In this study, we hypothesize that plastic leachates from accelerated photo-induced polymer breakdown products generated in artificial seawater cause impaired photosynthetic activity and cell growth in microalgae. To test this hypothesis, we investigated the toxicity of leachate waters from microplastics with large and trace amount additives. The microplastics with large amounts of additives were derived from consumer products, namely electronic waste (EW) and a keyboard plastic (KB). The EW investigated herein was derived from an e-waste recycling/sorting facility and was previously reported to contain flame retardants, antimony, bisphenol A, and polychlorinated biphenyls [14-16, 19]. As an electronic device, the KB was also expected to contain chemical mixtures of additives, based on detectable effects of KB leachates in reporter gene assays
[17]. The microplastic with trace/negligible amounts of additives was derived from pre-production polymer pellets of polyethylene (PE), polyethylene terephthalate (PET), polypropylene (PP), and polystyrene (PS), which mainly contained polymer residuals and degradation products of polymers because of artificial UV-weathering treatment to induce photo-oxidation.

To obtain further insights into the MoA of leachates from UV-weathered microplastic, we investigated whether polymer degradation products (carboxylic acids) previously identified as PE degradation products by Gewert et al. [20] have the potential to explain the observed algae toxicity. The observed biological responses were discussed in relation to estimated algae effect concentrations that elicit $50 \%$ of the maximum effect $\left(\mathrm{EC}_{50}\right.$ values) for baseline toxicity for these carboxylic acids as well as other additives for the EW by quantitative structure relationships by Altenburger et al. [21]. Finally, the data were compared to effect data derived from cell-based bioassays from Rummel et al. [17].

\section{Material and methods}

\section{Test materials and chemicals}

The test polymers PE, PET, PS, and PP were purchased from Goodfellow (Hamburg, Germany). Diuron (as positive control, CAS: 330-54-1, Sigma-Aldrich, Steinheim, Germany), methanol (MeOH), and ethylacetate (EtOAc) (HPLC-grade, $\geq 99.9 \%$, Honeywell Riedel de Haen, Fisher Scientific GmbH, Schwerte, Germany), sodium hydrogen carbonate (CAS 144-55-8, Sigma-Aldrich, Steinheim, Germany), ingredients for the Grimme Boardman (GB) medium [22], and LC-grade water were purchased from Optima ${ }^{\mathrm{TM}}$ Fisher Chemical (Reinbach, Suisse). Oasis HLB Plus (Waters GmbH, Eschborn, Germany) with 225 mg sorbent were used for solid-phase extraction (SPE) of the chemicals that leached from the test materials during artificial weathering. Mono- and dicarboxylic acids ( $\alpha, \omega$ position) of carbon chain lengths of $\mathrm{C} 5, \mathrm{C} 7-\mathrm{C} 12, \mathrm{C} 14, \mathrm{C} 16$, and $\mathrm{C} 18$ were purchased from Sigma-Aldrich (Steinheim, Germany) (for detailed information see Table S1 of the Electronic Supplementary Material (ESM)).

\section{Leachates}

For each polymer type, EW, KB, PE, PET, PP, and PS, $200 \mathrm{~mL}$ of aqueous leachates were generated in triplicates as described in Rummel et al. [17] and in section S1 Test Polymers (ESM). Briefly, $50 \mathrm{~g}$ of milled polymer material $<300 \mu \mathrm{m}$ was artificially weathered in artificial seawater (ASW, Instant Ocean ${ }^{\circledR}$ (Blacksburg, VA, USA at $35 \mathrm{~g} / \mathrm{L}$ ) using a strong UV light source (OSRAM Supratec 
HTC400-241 R7s UVA/UVB lamp) in a rotating wheel to guarantee constant mixing (hereafter named "UV" samples). Dark controls were leached in the same manner but without UV light exposure (hereafter named "DC"). To account for any background contamination, three procedural blanks were generated following the entire leachate preparation protocol but without any polymer. After the weathering treatment, microplastic particles were filtrated to yield the $200 \mathrm{~mL}$ of leachate water only, which was then enriched via solidphase extraction (SPE, HLB Plus Oasis cartridges, $225 \mathrm{mg}$, Waters GmbH, Eschborn, Germany). Additionally, four SPE blanks generated by enriching $200 \mathrm{~mL}$ LC-grade water were tested for potential background effects by the SPE enrichment. After enrichment, the SPE cartridges were rinsed with $10 \mathrm{~mL}$ of LC-grade water to eliminate salt residues in the sorbents. After drying for $2 \mathrm{~h}$ under vacuum in the manifold, the SPE cartridges were stored at room temperature in the dark. Following elution with EtOAc and $\mathrm{MeOH}$ and solvent evaporation, the samples were re-dissolved in $1 \mathrm{~mL}$ of $\mathrm{MeOH}$ for testing. This procedure resulted in an enrichment factor (EF) of 200 based on the aqueous leachate $(200 \mathrm{~mL})$ and final methanolic sample volume $(1 \mathrm{~mL})$ (for details, see Supporting Information in Rummel et al. [17]).

\section{Exposure}

To study the effects of microplastic leachates towards microalgae, a miniaturized high-throughput algae assay based on the OECD guideline No. 201 (Freshwater Alga Growth Inhibition Test, OECD [18]) was used. In this test setup, a synchronized culture of the unicellular green algae Scenedesmus vacuolatus, cultivated in GB medium, was exposed to the test material leachates in a 96-well plate (see Figure S2 A, ESM). Aliquots of the leachates were blown down to dryness, re-dissolved in GB medium, and diluted serially 1:2 in the well plate with 10 dilution steps. Concentrations in the bioassays of enriched leachates are given as the product of the SPE enrichment factor of 200 and the dilution factor from the serial dilution resulting in the relative enrichment factor (REF). The highest tested relative enrichment factor $(\mathrm{REF})$ was $\mathrm{REF}=197.8$. Negative controls contained GB medium only. For positive controls, reference cells were exposed to the photosystem II inhibitor Diuron [23] at $1.17 \mu \mathrm{mol} / \mathrm{L}$ as the highest test concentration, eliciting $100 \%$ effect. After verifying the absence of any interfering autofluorescence of the samples using a microplate fluorescence reader (Spectra Max Gemini EM, Molecular Devices, San Jose, USA), $15 \mu \mathrm{L}$ of algae suspension were added to each well with a final algae density of $7.5 \times 10^{4}$ cells $/ \mathrm{mL}$ with a total volume of $150 \mu \mathrm{L}$ per well. Plates were sealed with Parafilm and LED day light-exposed for $24 \mathrm{~h}$ at $300 \mathrm{rpm}$ rotation and $28{ }^{\circ} \mathrm{C}$ in a Multitron incubator (Infors, Bottmingen, Germany).
Chlorophyll $a$ autofluorescence, as a representative biological effect parameter for biomass, was measured $2 \mathrm{~h}$ after the addition of algae and after $24 \mathrm{~h}$ of exposure. Cell density, indicating cell growth and/or growth inhibition, was determined using a FACSCelesta (BD Biosciences, NJ, USA) instrument after $24 \mathrm{~h}$ of exposure. Furthermore, we determined the photosynthetic capacity as maximum quantum yield (Yield I (YI)) and effective quantum yield (Yield II (YII)) after $2 \mathrm{~h}$ and $24 \mathrm{~h}$ of exposure using the Imaging PAM Chlorophyll Fluorometer (M-series, Heinz Walz GmbH, Effeltrich, Germany) (see Figure S2 B, ESM).

\section{Data analyses}

Algae growth rates were calculated based on the Chlorophyll $a$ autofluorescence and details are described in section S2 Data Analyses (ESM). For the other parameters, cell densities and the photosynthetic yields YI and YII after $2 \mathrm{~h}$ and $24 \mathrm{~h}$ of exposure, the measured values were used for the calculation of the relative inhibition to controls (in percent (\%)) without background subtraction (section S2 Data Analyses, ESM).

Analogously to Rummel et al. [17], effect units (EU) for the parameter autofluorescence $\left(\mathrm{EU}_{\text {fluo }}\right)$ or cell density $\left(\mathrm{EU}_{\text {cell }}\right)$ were calculated as the inverse $\mathrm{EC}_{50}$ value (i.e., in the unit $1 / \mathrm{REF})$. If all three tested replicates of a sample type resulted in a measurable effect, the mean and the $95 \%$ confidence interval were calculated for the triplicates to facilitate comparison between samples.

Gewert et al. [20] confirmed the presence of carboxylic acids in aqueous leachates from the identical UV-weathered virgin test polymers, for which we observed effects in reporter gene assays in our previous work [17]. Hence, we tested a set of mono- and dicarboxylic acids ( $\alpha, \omega$ position) of different carbon chain lengths of C5, C7-C12, C14, $\mathrm{C} 16$, and $\mathrm{C} 18$ in the microalgae bioassay to investigate their potential to cause algae toxicity.

We applied a quantitative structure-activity relationship QSAR for the applied algae test system [21] to predict $\mathrm{EC}_{50}$ values of baseline toxicity of the carboxylic acids towards microalgae (Eq. 1). This QSAR is based on the hydrophobicity $\left(K_{\mathrm{ow}}\right)$ of the chemical of investigation. However, at the applied pH of 7.0 in the assay, the carboxylic acids will fully dissociate and be present in their anionic form, for which the cellular uptake is slower and lower [24]. To account for speciation, the partition coefficient between liposomes and water, $K_{\text {lipw }}$, of the neutral species of the carboxylic acids was predicted by the log$K_{\text {ow }}$-based QSAR by Endo et al. [25] (Eq. 2). The fraction of the neutral species was calculated using the HendersonHasselbalch equation from the acidity constant $\mathrm{p} K_{\mathrm{a}}$ (taken from PubChem, predicted using SPARC or assumed at $\mathrm{p} K_{\mathrm{a}}=4.9$, see Table $\mathrm{S} 2$ section S3 QSAR Data). Baseline 
Fig. 1 Radar plots of the effect unit values $\left(\mathrm{EU}=\right.$ inverse $\mathrm{EC}_{50}$ values) of the different effect parameters of leachates from the EW microplastics following UV light (UV, in triplicates UV_1-3, A) and dark control (in triplicates DC_4-6, B) treatments tested in microalgae. The effect parameters presented are fluorescence, cell densities, and photosynthetic yield I and II after $2 \mathrm{~h}$ or $24 \mathrm{~h}$ (YI2h, YII2h, YI24h, and YII24h) of exposure, respectively. The EU scale corresponds to the inverse relative enrichment factor (REF) [unit $L_{\text {bioassy }} / L_{\text {water }}$ ]

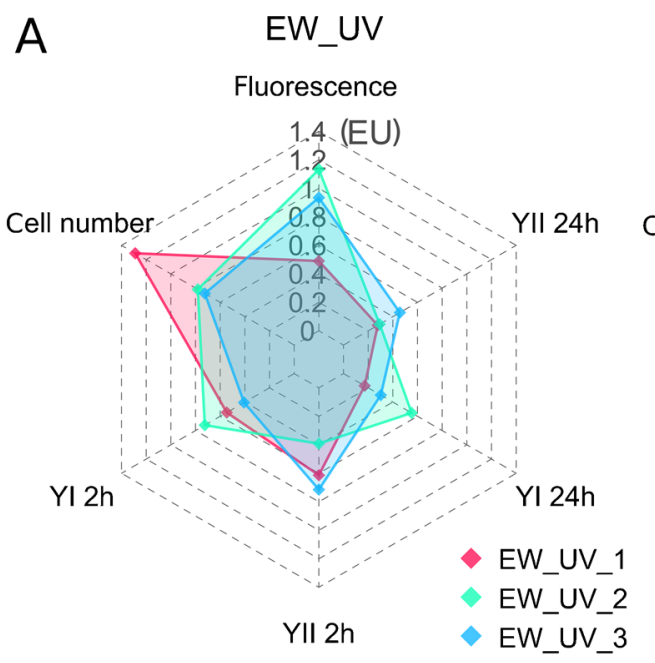

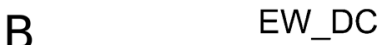

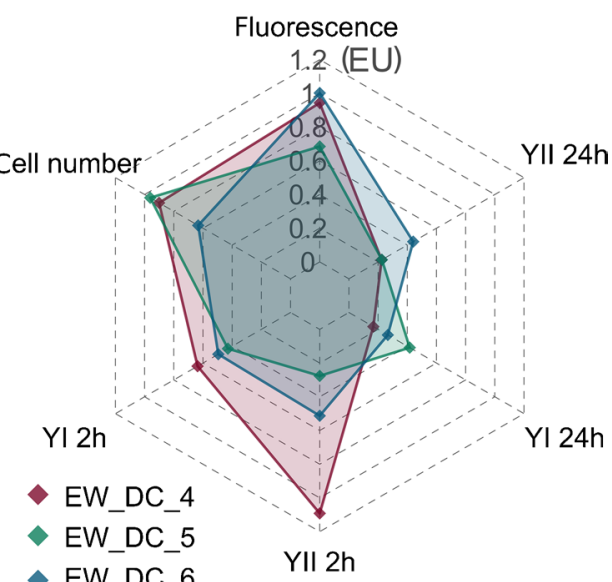

toxicity values of the neutral fraction using the ionization-corrected liposome/water distribution ratios $\left[D_{\text {lip/w }}\right.$ (pH 7.0)] (Eq. 3) were calculated following Escher et al. [26] (Eq. 4), parameterized with the converted slope and intercept of the QSAR by Altenburger et al. [21] (Eq. 1) by replacing $\log K_{\text {ow }}$ by $\log K_{\text {lipw }}$ of Endo et al. [25] (Eq. 2) (see details in section S3, Table S2, ESM).

$\log E C_{50}\left(\frac{m o l}{L}\right)=-0.863 * \log K_{o w}-0.897[21]$

$\log K_{\text {lipw }}($ neutral $)=1.01 * \log K_{\text {ow }}-0.12[25]$

$\log D_{\text {lipw }}(p H 7.0)=f_{\text {neutral }} * \log K_{\text {lipw }}+f_{\text {ionized }} *\left(\log K_{\text {lipw }}-1\right)[26]$

$\log \left(1 / E C_{50, \text { basline }}\right)\left(\frac{m o l}{L}\right)=-0.855 * \log D_{\text {lipw }}(p H 7.0)-1.02$

As an effect diagnostic tool, we calculated the toxic ratios (TRs, Eq. 5) between the predicted baseline toxicity (Eq. 4) and the measured effect data of the parameters fluorescence and cell density to differentiate baseline toxicity from potential specific MoAs of microplastic degradation products towards the photosystem (here: mono- and dicarboxylic acids). We consider a specific MoA to occur when the TR ranges $>10$ [26]. To further confirm non-specific effects of degradation products of the polymers, the cytotoxicity values of the bioassay from our previous work published in Rummel et al. [17] (inverse $\mathrm{IC}_{10}$ as $\mathrm{TU}_{\text {bio }}$ ) were correlated to the apical parameters fluorescence and cell density of algae growth to further investigate baseline toxicity. To enable comparison to this former study [17], $\mathrm{EC}_{10}$ values for microalgae were calculated from the $\mathrm{EC}_{50}$ values based on Eq. 6 .
$T R=\frac{\text { predictedEC } C_{50(\text { baseline })}}{\text { measured } E C_{50}}$

$$
\begin{aligned}
E C_{x} & =\left(\frac{x}{100-x}\right)^{1 / h} * E C_{50} \\
x & =x \% \text { effect (here } x=10) \\
h & =\text { Hill slope }
\end{aligned}
$$

To estimate the percent effect explained by chemicals previously determined in the EW material, we calculated the potential mass concentrations in the leachates for several polychlorinated biphenyls (PCBs), polybrominated diphenyl ethers (PBDEs), and bisphenol A (BPA) by mass balancing (section S4 Iceberg Modelling, eq.S3-eq.S6). Applying the above-mentioned QSAR for baseline algae toxicity [21], we estimated the respective $\mathrm{EC}_{50}$ concentrations and effect contributions by each chemical $(i)$ and summed them up in a so-called iceberg model based on the concentration addition model to estimate the effect units elicited by the known chemicals $\left(\mathrm{EU}_{\text {chem }}\right)[27,28]$. Comparing $\mathrm{EU}_{\text {chem }}$ to $\mathrm{EU}_{\text {fluo }}$ or $\mathrm{EU}_{\text {cell }}$ gives a rough estimate of the effect contribution of the known leachate mixture to the observed total biological responses (for details, see section S4 Iceberg Modelling, Table S3, Table S4, ESM).

\section{Results}

\section{Effects of microplastic leachates}

When testing microplastic leachates from different polymer types in microalgae, the growth-based apical parameters (autofluorescence and cell densities) were more responsive than photosynthesis inhibition (YI and YII) (Fig. 1A, B, Table S5, ESM). Therefore, these two apical 

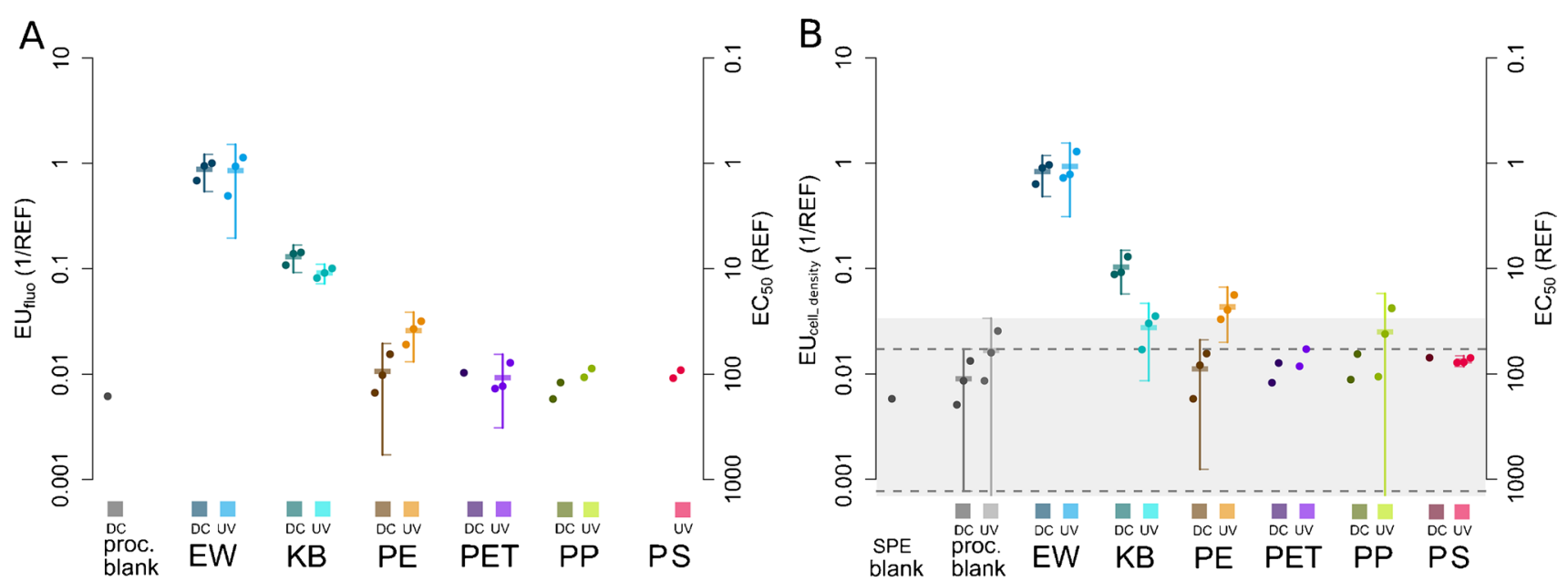

Fig. 2 Effect units (EU, 1/REF $\left[L_{\text {bioassay }} / L_{\text {water }}\right]$ ) of Chl a autofluorescence (A) and cell density (B) inhibition of microalgae $S$. vacuolatus exposed to leachates from microplastics containing additives (EW, KB) and largely additive-free polymers (PE, PET, PP, and PS). EUs (left axis) are given as the inverse $\mathrm{EC}_{50}$ to facilitate association of high toxicity with high values; $\mathrm{EC}_{50}$ is additionally given as the scale to the right (unit REF $\left[L_{\text {water }} / L_{\text {bioassay }}\right]$ ). Leachates were generated under UV light (UV) and dark control conditions (DC) in triplicates (single data points). If all triplicates caused measurable effects, the mean and $95 \%$ confidence interval were calculated and depicted as boxes and whiskers. Comparison to procedural blanks is facilitated by the dotted dashed line and grey shaded area in $\mathbf{B}$ (not in $\mathbf{A}$ since none of the different triplicate blanks elicited effects on Chlorophyll $a$ fluorescence). Missing values indicate the absence of measurable effects at the tested concentrations REF $<198$

parameters were chosen for subsequent comparisons between samples.

Only the EW and KB induced effects on all measured effect parameters whereas effects of the test polymer leachates could only be observed on algal growth based on Chlorophyll $a$ autofluorescence indicative for biomass, as well as cell densities indicative for cell growth inhibition (Fig. 1, Fig. 2, Table S5, ESM). For EW and KB, the photosynthetic capacity was less affected after $24 \mathrm{~h}$ after dosing (YI and YII $24 \mathrm{~h}$ ) compared to the $2 \mathrm{~h}$ measurements (YI and II $2 \mathrm{~h}$, Fig. 1A and B). Only one of the three dark control (DC) procedural blanks negatively affected the fluorescence of $S$. vacuolatus (Fig. 2A). No effects on the fluorescence could be detected for the SPE and the UV light-treated blanks. The EW caused a decrease in the Chlorophyll $a$ fluorescence compared to unexposed microalgae at mean EU values and standard deviations of $\mathrm{EW}_{\mathrm{DC}}=0.88 \pm 0.17$ and $\mathrm{EW}_{\mathrm{UV}}=0.85 \pm 0.32$. Interestingly, the UV light-irradiated $\mathrm{PE}_{\mathrm{UV}}$ showed higher adverse effects on microalgae compared to its dark control $\mathrm{PE}_{\mathrm{DC}}$ for the effect parameters fluorescence and cell densities (Fig. 2A, B). For the remaining polymers $\mathrm{PET}$, $\mathrm{PP}$, and PS, measurable effects were not reproduced in each replicate $(n=3)$.

One SPE blank and all replicates of the procedural blanks (DC and UV) resulted in detectable effects on the algae cell densities (Fig. 2B, Table S5, ESM). Whereas EW showed similarly high EU mean values for DC and UV treatments of $\mathrm{EW}_{\mathrm{DC}}=0.83 \pm 0.18$ and $\mathrm{EW}_{\mathrm{UV}}=0.93 \pm 0.3$, $\mathrm{KB}_{\mathrm{UV}}$ displayed a much lower effect potency than $\mathrm{KB}_{\mathrm{DC}}$.
$\left(\mathrm{KB}_{\mathrm{DC}}=0.10 \pm 0.02, \mathrm{~KB}_{\mathrm{UV}}=0.03 \pm 0.01\right)$. As observed for Chlorophyll $a$ fluorescence inhibition, $\mathrm{PE}_{\mathrm{UV}}$ induced four times higher effects towards algae cell densities than $\mathrm{PE}_{\mathrm{DC}}$. Noteworthy, most of the observed effects on cell densities for the tested additive-free polymer leachates were in the range of the corresponding procedural blanks except $\mathrm{PE}_{\mathrm{UV}}$ which differed from the corresponding blanks.

The EW elicited the most explicit effects, and the effects on Chlorophyll $a$ fluorescence and cell densities exhibited the highest $\mathrm{EU}_{\text {bio }}$ values $\left(\mathrm{EC}_{\text {fluo }}\left(\mathrm{EW}_{\mathrm{DC} \text { or UV }}\right)=0.49-1.1\right.$; $\left.\mathrm{EC}_{\text {cell }}\left(\mathrm{EW}_{\mathrm{DC} \text { or UV }}\right)=0.63-1.29\right)$ in contrast to the photosynthetic yield (YI/II 2-24 h ( $\mathrm{EW}_{\mathrm{DC}}$ or $\left.\left.\mathrm{EW}_{\mathrm{UV}}\right)=0.17-1.09\right)$ (Fig. 2, Table S5, ESM). Photosynthesis was adversely affected mainly by the leachates from EW and KB as well as by the PE leachates (DC and UV) (Table S5, ESM). PE generally showed stronger adverse effects to YI and YII compared to $\mathrm{PE}_{\mathrm{DC}}$ and was within the range of the effects observed for EW and KB leachates. Furthermore, $\mathrm{EC}_{50}$ increased after $24 \mathrm{~h}$ of exposure compared to $2 \mathrm{~h}$ after dosing (Table S5, ESM). PET, PP, and PS showed minor effects towards microalgae and, if detectable, they were mostly within the range of the blanks (Fig. 2, Table S5, ESM).

\section{Effects elicited by polymer degradation products}

When testing mono- and dicarboxylic acids in the microalgae test at the highest soluble concentrations, mainly the monocarboxylic acids resulted in detectable effects (Table 1). Only dicarboxylic acids of carbon chain lengths 
Table 1 QSAR and effect data of mono- and dicarboxylic acids tested in the microalgae test system

\begin{tabular}{|c|c|c|c|c|c|c|}
\hline Substance & CAS & MW & $\log P_{\mathrm{ow}}\left[\mathrm{L}_{\mathrm{w}} / \mathrm{L}_{\mathrm{o}}\right]$ & $\mathrm{QSAR} \mathrm{EC}_{50}[\mathrm{mM}]^{\mathrm{d}}$ & $\begin{array}{l}\mathrm{EC}_{50} \text { fluorescence } \\
{[\mathrm{mM}]}\end{array}$ & $\begin{array}{l}\mathrm{EC}_{50} \text { cell } \\
\text { density } \\
{[\mathrm{mM}]}\end{array}$ \\
\hline Pentanoic acid & $109-52-4$ & 102.13 & $1.39^{\mathrm{a}}$ & 51.59 & 14.49 & 9.18 \\
\hline Pentanedioic acid & $110-94-1$ & 132.12 & $0.256^{\mathrm{a}}$ & 1561.30 & 268.59 & 174.54 \\
\hline Heptanoic acid & $111-14-8$ & 130.19 & $2.42^{\mathrm{a}}$ & 6.99 & 1.11 & 0.60 \\
\hline Heptanedioic acid & $111-16-0$ & 160.17 & $0.61^{\mathrm{a}}$ & 258.82 & ND & 140.97 \\
\hline Octanoic acid & $124-07-2$ & 144.2 & $3.05^{\mathrm{a}}$ & 1.74 & 0.49 & 0.19 \\
\hline Octanedioic acid & $505-48-6$ & 174.20 & $1.21^{\mathrm{b}}$ & 112.91 & ND & ND \\
\hline Nonanoic acid & $112-05-0$ & 158.24 & $3.4^{\mathrm{a}}$ & 0.94 & 1.35 & 0.39 \\
\hline Nonanedioic acid & $123-99-9$ & 188.22 & $1.57^{\mathrm{a}}$ & 35.27 & ND & ND \\
\hline Decanoic acid & $334-48-5$ & 172.27 & $4.09^{\mathrm{a}}$ & 0.24 & ND & 1.45 \\
\hline Decanedioic acid & $111-20-6$ & 202.25 & $2.19^{b}$ & 28.10 & ND & ND \\
\hline Undecanoic acid & $112-37-8$ & 186.30 & $4.42^{\mathrm{a}}$ & 0.13 & ND & ND \\
\hline Undecanedioic acid & $1852-04-6$ & 216.28 & $2.8^{\mathrm{c}}$ & 6.99 & ND & ND \\
\hline Dodecanoic acid & $143-07-7$ & 200.32 & $4.6^{\mathrm{a}}$ & 0.08 & ND & ND \\
\hline Dodecanedioic acid & $693-23-2$ & 230.30 & $3.17^{\mathrm{b}}$ & 3.16 & ND & ND \\
\hline Tetradecanoic acid & $544-63-8$ & 228.38 & $6.1^{\mathrm{a}}$ & 0.005 & ND & ND \\
\hline Tetradecanedioic acid & $821-38-5$ & 258.36 & $4.3^{b}$ & 2.12 & ND & ND \\
\hline Hexadecanoic acid & $57-10-3$ & 256.43 & $7.2^{\mathrm{a}}$ & 5.10E-04 & ND & ND \\
\hline Octadecanoic acid & $57-11-4$ & 284.48 & $8.23^{\mathrm{a}}$ & $6.99 \mathrm{E}-05$ & ND & ND \\
\hline
\end{tabular}

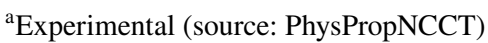

${ }^{\mathrm{b}}$ Computed by XLogP3 3.0 (PubChem release 2019.06.18)

${ }^{\mathrm{c}}$ Safety data sheet

${ }^{\mathrm{d}}$ Calculated by quantitative structure relation by Altenburger et al. [21]

$N D$ not detected

C5 and C7 resulted in measurable effects whereas monoand dicarboxylic acids of carbon chain lengths greater than eleven did not generally cause algae toxicity or impairment of the photosystem. Most of the calculated TRs for the growth-based effect parameters (fluorescence and cell densities) were located in a narrow range of $1<\mathrm{TRs}<10$ except for two carboxylic acids that were outliers above and below these thresholds (Fig. 3A).

\section{Effect diagnostics}

We correlated the results for cytotoxicity obtained using reporter gene bioassays from Rummel et al. [17] with the microalgae test results (correlation to cytotoxicity of the aryl hydrocarbon receptor assay AhR CALUX [29, 30] shown in Fig. $3 \mathrm{~B}, \mathrm{C}$ ). Here, calculating the $\mathrm{EC}_{10}$ values for the microalgae test results was necessary to facilitate a comparison to the $\mathrm{EC}_{10}$ and the inverse effect units $\left(\mathrm{EU}_{\mathrm{bio}}\right)$ and toxic units $\left(\mathrm{TU}_{\mathrm{bio}}\right)$ derived in the bioassay. Linear regressions of the microalgae test data as a function of reporter gene cytotoxicity $\left(\mathrm{TU}_{\mathrm{bio}}\right)$ resulted in statistically significant correlations in many cases with slopes close to one (Fig. 3B, C, Table S6, ESM) (see also 1:1 line in Fig. 3B, C).
In addition, we applied a two-phase partitioning model to calculate the amount of PBDEs, PCBs, and BPA potentially having leached into the leachate water from e-waste based on equilibrium partitioning. Calculated aqueous concentrations ranged from $8.3 \mathrm{E}-18 \mathrm{~mol} / \mathrm{L}_{\mathrm{ASW}}$ for hexabromobiphenyl \#153 to $6.5 \mathrm{E}-07 \mathrm{~mol} / \mathrm{L}_{\mathrm{ASW}}$ for BPA (Table S4, ESM). These concentrations were used to calculate relative effect contributions of each individual chemical $(i)\left(\mathrm{EU}_{\mathrm{chem}(i)}\right)$ and summed up in a concentration-additive mixture model $\left(\mathrm{EU}_{\text {chem }}\right)$. Applying this so-called iceberg modelling (see details in section S4 Iceberg Modelling, Table S3, Table S4, ESM), we could explain less than $1.5 \%$ of the observed biological effects of the parameters fluorescence and cell density by $\mathrm{EU}_{\text {chem }}$ for the EW samples (Table S7, ESM), indicating their small contribution to the overall effect.

\section{Discussion}

\section{Effects from the leachates}

Mostly EW and KB resulted in measurable adverse effects on the microalgae test system. A reason for the strong 

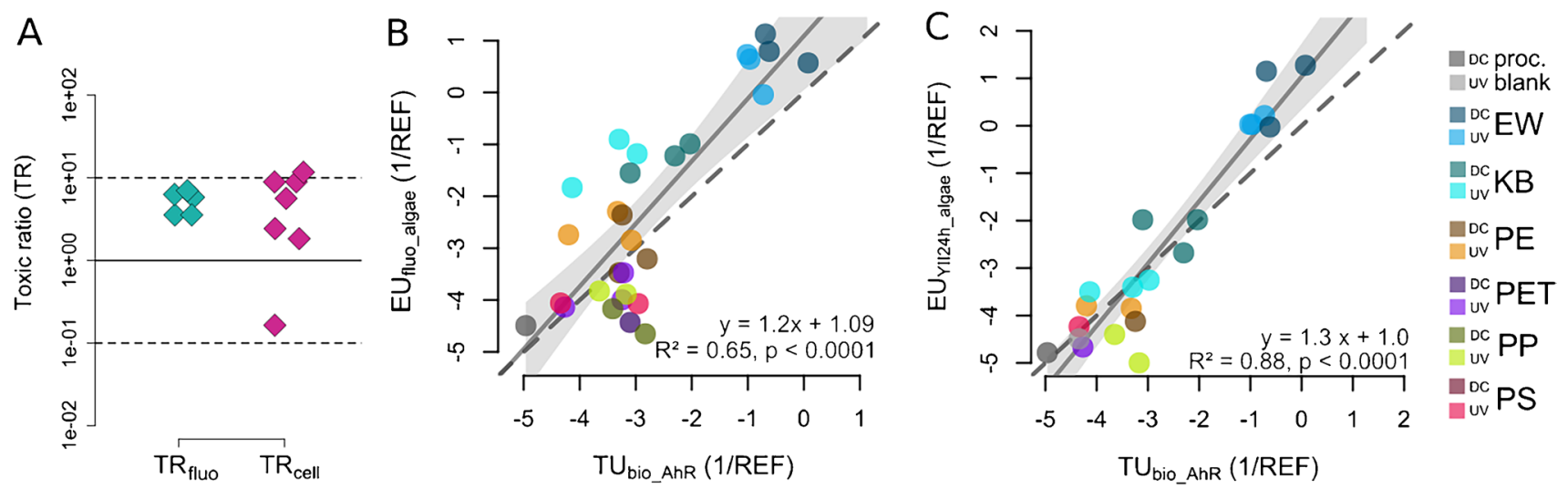

Fig. 3 A Toxic ratios (TRs) for mono- and dicarboxylic acids (C5-C18) tested in the microalgae test with measured effect parameters for autofluorescence (fluo) and cell densities (cell). B Statistically significant correlations between cell-based assay data [17] and microalgae data (this study) were observed and confirmed by the linear regression of the apical observation parameter fluorescence for microalgae (fluo_algae) as a function of toxic units $\left(\mathrm{TU}_{\mathrm{bio}}\right)$ of the specific effects in the AhR assay (regression parameters, coefficient of determination, and $p$-value are included in the plot, log-transformed data). C Statistically significant correlation of $\mathrm{TU}_{\text {bio }}$ in the AhR assay and the photosynthetic activity at $24 \mathrm{~h}$ after dosing for the microalgae $\left(\mathrm{EU}_{\mathrm{YII} 24 \mathrm{~h} \text { algae }}\right.$, log-transformed). Dashed lines in B and $\mathrm{C}$ represent the 1:1 line which corresponds to a 1:1 correlation. Color codes for B and C show the different polymer types with respective dark controls (DC) and UV-irradiated (UV) weathering treatments

toxicity caused by their leachates may be the high amount of additives that has been determined in the EW and can be assumed to be present in the KB. Previous chemical-analytical studies revealed high concentrations of PBDEs, PCBs, and BPA (e.g., $\sum$ BDE-10 up to $210 \mathrm{mg} / \mathrm{kg}_{\mathrm{EW}}, \sum \mathrm{PCB}_{7}$ up to $1.3 \mathrm{mg} / \mathrm{kg}_{\mathrm{EW}}$, and BPA up to $188 \mathrm{mg} / \mathrm{kg}_{\mathrm{EW}}$ ) in the EW material [14-16]. The KB, as an electronic device, was assumed to contain substantial amounts of additives for its application purpose. Although these substances may not act specifically on the photosystem, as indicated by their low potency to inhibit the photosynthetic capacity, their relatively high inhibition potency on the growth-based parameters (Figs. 1 and 2) indicates their environmental relevance. Baseline toxicity is the minimum toxicity a chemical can exhibit which is concentration-additive, and thereby a diverse range of different chemicals in EW and KB may act jointly in baseline toxicity.

Estimating the effect contribution of the sum of chemicals previously measured in the exhaustive solvent-extracted EW (PBDEs, PCBs, and BPA) [14-16] and that can be expected to be present in the leachates, we could explain $<1.5 \%$ of the observed biological effects (see Table S7, ESM). Although this modeled data is based on several assumptions such as equilibrium partitioning and QSAR-derived effect concentrations, we can draw two conclusions: firstly, despite advanced instrumentation and in-depth chemical analyses by exhaustive solvent extraction and targeted gas chromatography coupled to mass spectrometry [14-16], there is still a substantial lack of knowledge regarding which representatives of a wide universe of chemicals present in EW contribute to the observed effects. Secondly, even though the modeled data presented above was based on a worst case scenario assuming equilibrium partitioning conditions which is unlikely in the applied relatively short-term 4-day weathering experiment, the explained effects remained in a very low range ( $>98 \%$ of the effects remained unexplained by the model). Comparably low fractions of toxicity explained by advanced chemical analytical tools were found in other studies (e.g., Neale et al. [31]). This fact highlights the great benefit of effect-based tools for risk assessment of potential hazards from plastic leachates, which could hardly be predicted by chemical analytical tools, even if advanced methods were applied, as, e.g., in the studies of Arp et al. [14] and Morin et al. [15, 16]. Capolupo and colleagues [32] directly linked the high toxicity of leachates of car tire rubber and polyvinyl chloride (PVC) on freshwater and marine microalgae to high contents of additives. A study by Chae et al. [33] investigated the toxicity of expanded polystyrene (EPS) towards four microalgae species. Generally, the photosynthetic activity of all four species was enhanced by EPS leachates [33]. The authors hypothesized about this hormesis effect that leaching DOC (such as the measured hexabromocyclododecanes, BPA, and UV-absorber UV326) might have promoted photosynthetic activity and thereby cell growth [33]. Previous studies have also explained such observations by trace concentrations of plastic additive chemicals [34].

Leachates from additive-free pre-production polymers PET, PP, and PS did not show detectable ecotoxicological effects on algae growth or photosynthetic activity in our study (Fig. 2, Table S5, ESM). The measurable effects barely differed from the respective blanks as seen for the parameter cell density (grey shaded area, Fig. 2B) indicating low risks from the virgin material of these polymers itself. This means that no specific toxicity such as inhibition of the photosystem was induced by substances leaching from weathered PET, PP, and PS microplastic in UV light or in dark treatments. 
One reason for the relatively low ecotoxicological potential of pre-production plastics may be the absence of additives and toxic degradation products of PET, PP, and PS.

Whereas in our study only PE showed algae toxicity to some extent, Tetu et al. [10] detected impaired growth, photosynthetic capacity, and genome-wide transcriptional changes by PE and PVC leachates for an important primary producer, Prochlorochoccus spec. Whereas adverse effects of plastic leachates were reduced by weathering in one study [35], we identified 2- to threefold increased toxicity for $\mathrm{PE}_{\mathrm{UV}}$ compared to $\mathrm{PE}_{\mathrm{DC}}$. Interestingly, $\mathrm{KB}$ showed similar reduced effects upon weathering as described by Tetu et al. [10] which could be indicative for the photo-degradation of toxic substances leaching from the material, to less toxic transformation products. Similar to the results of Rummel et al. [17], prominent effects were caused by EW with $\mathrm{EC}_{50}$ values of REFs around or below $\mathrm{EC}_{50} \leq 1$ (REF) (or reciprocal EU values $\geq 1$ (1/ REF)) meaning that no dilution or enrichment from the original $200 \mathrm{~mL}$ leachate was necessary to target the observed effect. Contrarily, the leachates from pre-production polymers had to be enriched by factors of 18 to 190 to elicit effects.

\section{MoA of PE degradation products}

The observed elevated $\mathrm{EU}$ values for $\mathrm{PE}_{\mathrm{UV}}$ compared to $\mathrm{PE}_{\mathrm{DC}}$ may potentially be the result of photo-oxidizing of the PE polymer, resulting in larger fractions of polymer breakdown products in the leachates (Fig. 2, Table S5, ESM). Gewert et al. [20] and Rummel et al. [17] identified degradation products in leachates that were generated using the identical weathering setup. Similar to Rummel et al. [17], where monocarboxylic acids showed more explicit effects in cells than dicarboxylic acids of comparable carbon chain length, the monocarboxylic acids showed a higher potential to elicit adverse effects on microalgae. The analytically identified degradation products of $\mathrm{PE}$, mainly dicarboxylic acids of different chain lengths (C5-C18), showed effects on all measured parameters; however, only acids with short carbon chain length $(<\mathrm{C} 10)$ and at high tested concentration were active (Table 1). Still a trend of increasing effects with increasing carbon chain length could be observed. This increase may relate to the acids' linear relationship between membrane permeability, as can be correlated with the hexadecane/water partition coefficient [36].

Applying the modified QSAR of Altenburger et al. [21], we predicted baseline toxicity for the investigated carboxylic acids and calculated resulting TRs. The observed TRs were $<10$ for almost all acids for the effect parameters fluorescence and cell density and were in good agreement with the non-specific disturbance of the cell membrane elicited by the acids. Moreover, the growth-based effect parameters of the microalgae test displayed a very narrow range of TRs indicating good agreement between calculated and measured $\mathrm{EC}_{50}$ values supporting their baseline toxic MoA (Fig. 3A). Based on the values of $1<\mathrm{TR}<10$ for the effect parameters fluorescence and cell densities (Fig. 3A), it can be assumed that the critical membrane concentration of $70 \mathrm{mmol} / \mathrm{L}_{\text {lip }}$ resulting in destabilization of the phospholipid bilayer was reached by the carboxylic acids [37], but there were no specific effects on the photosystem II. The applied QSAR may potentially not be adequate for photosystem II inhibition since its main purpose was to calculate baseline toxicity values for integrated parameters like growth inhibition.

Cellular membranes contain unsaturated fatty acids [38] that are especially prone to attack by free radicals causing lipid peroxidation [39], lysis [40], and fatty acid deesterification [41]. In this context, fluorescence as a measure of growth is a good indicator of membrane disintegration, which is dependent on the hydrophobicity of the exposed chemicals. Fluorescence could therefore indicate baseline toxicity. These observations compare well to the finding discussed above that the apical parameters fluorescence and cell densities were the most sensitive parameters in the leachate tests (Fig. 1). Furthermore, the EU values of fluorescence correlated statistically significantly with the cytotoxicity values derived from reporter gene assays with regression slopes close to one (Fig. 3B, C, Table S6, ESM). The similarly good correlation to cytotoxicity of reporter gene assays therefore suggests that the impairment of the photosystem is an indirect effect of baseline toxicity (Fig. 3B, C, Table S6, ESM).

In a comparable way, the AREc 32 cell assay, responsive to oxidative stress, was induced across all tested polymer types in Rummel et al. [17]. At high physiological concentrations, reactive oxygen species may cause cell damage and cell death [42] often induced by small reactive molecules [43]. Another indication for baseline toxicity as the underlying mechanism of toxicity was the good correlation and regression slopes close to 1 between cytotoxicity values $\left(\mathrm{TU}_{\mathrm{bio}}\right)$ from the AhR assay and $\mathrm{EU}_{\text {bio }}$ values of the AREc32 assay (Fig. 3, Table S6, ESM). Accuracy of the linear regression models could potentially be improved in the experimental setup if the same amount of plastic was used for the leaching experiment. In Rummel et al. [17], $50 \mathrm{~g}$ of each plastic type was leached into artificial seawater whereas in this study $40 \mathrm{~g}$ were applied in the weathering setup (note that this slight experimental difference is not reflected in the given concentrations in the assay, since identical enrichment factors, based on the same underlying volumetric measure of $200 \mathrm{~mL} \mathrm{ASW}$ in the weathering setup, were applied).

\section{Conclusion}

Additive-containing EW and KB caused strong adverse effects on microalgae growth and photosynthesis while leachates from virgin pre-production polymers PET, PP, and PS elicited effects in the range of the blanks. Though several target pollutants were identified in the EW, the known, quantified ones could only 
account for a small fraction of the observed effects $(<1.5 \%)$, indicating that other pollutants drive the observed toxicity, assuming the modeled assumptions were accurate. Elevated toxicity by UV-treated $\mathrm{PE}_{\mathrm{UV}}$ leachates could potentially be explained by the presence of small reactive molecules such as mono- and dicarboxylic acids that were very likely present in the leachates because of photo-oxidation. These degradation products were mainly baseline toxic since the measured data were consistent with predicted baseline toxicity values for the investigated carboxylic acids. Our findings highlight that degrading and largely additive-free pre-production polymers have the potential to induce adverse effects on whole organisms, particularly PE; however, stronger adverse effects were observed if the polymers contained additives or other chemicals. As a future step, advanced chemical analytical tools, e.g., effect-directed analysis combined with non-target screening, would be necessary to resolve the chemicals causing these effects $[44,45]$. Therefore, the application of effect-based tools provides a reliable strategy to assess potential environmental risks from potentially hazardous materials like plastics. To increase our understanding of chemical leachate vs. particle toxicity of plastics, future studies should investigate algae toxicity of migrating additives and compare them to toxicity caused by the mere presence of the particles, benchmarked to natural particle concentrations.

Supplementary Information The online version contains supplementary material available at https://doi.org/10.1007/s00216-021-03798-3.

Acknowledgements We gratefully acknowledge Matthew MacLeod and Oskar Sandblom for providing the plastic leachates. For helpful support on data generation, we would like to express many thanks to Silke Aulhorn. Sincere thanks go to Beate Escher for her scientific input and assistance in the data analyses.

Funding Open Access funding enabled and organized by Projekt DEAL. This work was done within the framework of the Joint Programming Initiative Healthy and Productive Seas and Oceans (JPI Oceans) project WEATHER-MIC (German Federal Ministry of Education and Research, BMBF, Grant \#03F0733A), the BMBF project MICROFATE (Grant \#03G0268TA), the Project P-LEACH (Helmholtz innovation pool "Changing Earth - Sustaining our Future" RA-470/20) and the Research Council of Norway (RCN, Project Grants 257433/E40 and SLUDGEFFECT 302371/E10).

\section{Declarations}

Conflict of interest The authors declare no competing interests.

Open Access This article is licensed under a Creative Commons Attribution 4.0 International License, which permits use, sharing, adaptation, distribution and reproduction in any medium or format, as long as you give appropriate credit to the original author(s) and the source, provide a link to the Creative Commons licence, and indicate if changes were made. The images or other third party material in this article are included in the article's Creative Commons licence, unless indicated otherwise in a credit line to the material. If material is not included in the article's Creative Commons licence and your intended use is not permitted by statutory regulation or exceeds the permitted use, you will need to obtain permission directly from the copyright holder. To view a copy of this licence, visit http://creativecommons.org/licenses/by/4.0/.

\section{References}

1. Anbumani S, Kakkar P. Ecotoxicological effects of microplastics on biota: a review. Environ Sci Pollut Res Int. 2018;25(15):1437396. https://doi.org/10.1007/s11356-018-1999-x.

2. Zhang C, Chen X, Wang J, Tan L (2017) Toxic effects of microplastic on marine microalgae Skeletonema costatum: Interactions between microplastic and algae. Environ Pollut 220, Part B:12821288. https://doi.org/10.1016/j.envpol.2016.11.005

3. Prata JC, da Costa JP, Lopes I, Duarte AC, Rocha-Santos T. Effects of microplastics on microalgae populations: a critical review. Sci Total Environ. 2019;665:400-5. https://doi.org/10. 1016/j.scitotenv.2019.02.132.

4. Sjollema SB, Redondo-Hasselerharm P, Leslie HA, Kraak MHS, Vethaak AD. Do plastic particles affect microalgal photosynthesis and growth? Aquat Toxicol. 2016;170:259-61. https:// doi.org/10.1016/j.aquatox.2015.12.002.

5. Rani-Borges B, Moschini-Carlos V, Pompêo M. Microplastics and freshwater microalgae: what do we know so far? Aquat Ecol. 2021. https://doi.org/10.1007/s10452-021-09834-9.

6. Deniel M, Lagarde F, Caruso A, Errien N. Infrared spectroscopy as a tool to monitor interactions between nanoplastics and microalgae. Anal Bioanal Chem. 2020;412(18):4413-22. https://doi.org/10.1007/s00216-020-02683-9.

7. Casabianca S, Capellacci S, Giacobbe MG, Dell'Aversano C, Tartaglione L, Varriale F, Narizzano R, Risso F, Moretto P, Dagnino A, Bertolotto R, Barbone E, Ungaro N, Penna A. Plastic-associated harmful microalgal assemblages in marine environment. Environ Pollut. 2019;244:617-26. https://doi.org/ 10.1016/j.envpol.2018.09.110.

8. Kettner MT, Oberbeckmann S, Labrenz M, Grossart HP. The eukaryotic life on microplastics in brackish ecosystems. Front Microbiol. 2019;10:538. https://doi.org/10.3389/fmicb.2019.00538.

9. Luo H, Xiang Y, He D, Li Y, Zhao Y, Wang S, Pan X. Leaching behavior of fluorescent additives from microplastics and the toxicity of leachate to Chlorella vulgaris. Sci Total Environ. 2019;678:1-9. https://doi.org/10.1016/j.scitotenv.2019.04.401.

10. Tetu SG, Sarker I, Schrameyer V, Pickford R, Elbourne LDH, Moore LR, Paulsen IT (2019) Plastic leachates impair growth and oxygen production in Prochlorococcus, the ocean's most abundant photosynthetic bacteria. Communications Biology 2 (1):184. https://doi.org/10.1038/s42003-019-0410-x

11. Hahladakis JN, Velis CA, Weber R, Iacovidou E, Purnell P. An overview of chemical additives present in plastics: migration, release, fate and environmental impact during their use, disposal and recycling. J Hazard Mater. 2018;344:179-99. https://doi. org/10.1016/j.jhazmat.2017.10.014.

12. Hermabessiere L, Dehaut A, Paul-Pont I, Lacroix C, Jezequel R, Soudant P, Duflos G. Occurrence and effects of plastic additives on marine environments and organisms: a review. Chemosphere. 2017;182:781-93. https://doi.org/10.1016/j.chemosphere.2017.05.096.

13. Groh KJ, Backhaus T, Carney-Almroth B, Geueke B, Inostroza PA, Lennquist A, Leslie HA, Maffini M, Slunge D, Trasande L, Warhurst AM, Muncke J. Overview of known plastic packaging-associated chemicals and their hazards. Sci Total Environ. 2019;651:3253-68. https://doi.org/10.1016/j.scitotenv.2018.10.015.

14. Arp HPH, Morin NAO, Andersson PL, Hale SE, Wania F, Breivik $\mathrm{K}$, Breedveld GD. The presence, emission and partitioning behavior of polychlorinated biphenyls in waste, leachate and aerosols from Norwegian waste-handling facilities. Sci Total Environ. 2020;715: 136824. https://doi.org/10.1016/j.scitotenv.2020.136824. 
15. Morin N, Arp HPH, Hale SE. Bisphenol A in solid waste materials, leachate water, and air particles from Norwegian waste-handling facilities: presence and partitioning behavior. Environ Sci Technol. 2015;49(13):7675-83. https://doi.org/10.1021/acs.est.5b01307.

16. Morin NAO, Andersson PL, Hale SE, Arp HPH. The presence and partitioning behavior of flame retardants in waste, leachate, and air particles from Norwegian waste-handling facilities. J Environ Sci (China). 2017;62:115-32. https://doi.org/10.1016/j.jes.2017.09.005.

17. Rummel CD, Escher BI, Sandblom O, Plassmann MM, Arp HPH, MacLeod M, Jahnke A. Effects of leachates from UV-weathered microplastic in cell-based bioassays. Environ Sci Technol. 2019;53(15):9214-23. https://doi.org/10.1021/acs.est.9b02400.

18. OECD (2011) Test No. 201: freshwater alga and cyanobacteria, growth inhibition test. https://doi.org/10.1787/9789264069923-en

19. Okkenhaug G, Almås ÅR, Morin N, Hale SE, Arp HPH. The presence and leachability of antimony in different wastes and waste handling facilities in Norway. Environ Sci Process Impacts. 2015;17(11):1880-91. https://doi.org/10.1039/C5EM00210A.

20. Gewert B, Plassmann M, Sandblom O, MacLeod M. Identification of chain scission products released to water by plastic exposed to ultraviolet light. Environ Sci Technol Lett. 2018;5(5):272-6. https://doi.org/10.1021/acs.estlett.8b00119.

21. Altenburger R, Walter $\mathrm{H}$, Grote $\mathrm{M}$. What contributes to the combined effect of a complex mixture? Environ Sci Technol. 2004;38(23):6353-62. https://doi.org/10.1021/es049528k.

22. Grimme LH, Boardman NK. Photochemical activities of a particle fraction P1 obtained from the green alga Chlorella fusca. Biochem Biophys Res Commun. 1972;49(6):1617-23. https://doi.org/10. 1016/0006-291X(72)90527-X.

23. van Rensen JJS (2008) Herbicides interacting with photosystem II. In: Dodge AD (ed) Herbicides and Plant Metabolism, vol 38. vol 38. Cambridge University Press, Cambridge, United Kingdom,

24. Fischer FC, Abele C, Droge STJ, Henneberger L, König M, Schlichting R, Scholz S, Escher BI. Cellular uptake kinetics of neutral and charged chemicals in in vitro assays measured by fluorescence microscopy. Chem Res Toxicol. 2018;31(8):646-57. https://doi. org/10.1021/acs.chemrestox.8b00019.

25. Endo S, Escher BI, Goss K-U. Capacities of membrane lipids to accumulate neutral organic chemicals. Environ Sci Technol. 2011;45(14):5912-21. https://doi.org/10.1021/es200855w.

26. Escher BI, Henneberger L, Konig M, Schlichting R, Fischer FC. Cytotoxicity burst? Differentiating specific from nonspecific effects in Tox 21 in vitro reporter gene assays. Environ Health Perspect. 2020;128(7):77007. https://doi.org/10.1289/EHP6664.

27. Neale PA, Escher BI. In vitro bioassays to assess drinking water quality. Current Opinion in Environmental Science \& Health. 2019;7:1-7. https://doi.org/10.1016/j.coesh.2018.06.006.

28. Neale PA, Brack W, Aït-Aïssa S, Busch W, Hollender J, Krauss M, Maillot-Maréchal E, Munz NA, Schlichting R, Schulze T, Vogler B, Escher BI. Solid-phase extraction as sample preparation of water samples for cell-based and other in vitro bioassays. Environ Sci Process Impacts. 2018;20(3):493-504. https://doi.org/10.1039/ c7em00555e.

29. Brennan JC, He G, Tsutsumi T, Zhao J, Wirth E, Fulton MH, Denison MS. Development of species-specific Ah receptor-responsive third generation CALUX cell lines with enhanced responsiveness and improved detection limits. Environ Sci Technol. 2015;49(19):11903-12. https://doi.org/10.1021/acs.est.5b02906.

30. Nivala J, Neale PA, Haasis T, Kahl S, König M, Müller RA, Reemtsma T, Schlichting R, Escher BI. Application of cell-based bioassays to evaluate treatment efficacy of conventional and intensified treatment wetlands. Environ Sci: Water Res Technol. 2018;4(2):206-17. https://doi.org/10.1039/C7EW00341B.

31. Neale PA, Braun G, Brack W, Carmona E, Gunold R, Konig M, Krauss M, Liebmann L, Liess M, Link M, Schafer RB, Schlichting R, Schreiner VC, Schulze T, Vormeier P, Weisner O, Escher BI.
Assessing the mixture effects in in vitro bioassays of chemicals occurring in small agricultural streams during rain events. Environ Sci Technol. 2020;54(13):8280-90. https://doi.org/10.1021/acs.est.0c02235.

32. Capolupo M, Sorensen L, Jayasena KDR, Booth AM, Fabbri E. Chemical composition and ecotoxicity of plastic and car tire rubber leachates to aquatic organisms. Water Res. 2020;169: 115270. https://doi.org/10.1016/j.watres.2019.115270.

33. Chae Y, Hong SH, An YJ. Photosynthesis enhancement in four marine microalgal species exposed to expanded polystyrene leachate. Ecotoxicol Environ Saf. 2020;189: 109936. https://doi.org/ 10.1016/j.ecoenv.2019.109936.

34. Chae Y, Kim D, An YJ. Effects of micro-sized polyethylene spheres on the marine microalga Dunaliella salina: focusing on the algal cell to plastic particle size ratio. Aquat Toxicol. 2019;216: 105296. https://doi.org/10.1016/j.aquatox.2019.105296.

35. Sarker I, Moore LR, Paulsen IT, Tetu SG. Assessing the toxicity of leachates from weathered plastics on photosynthetic marine bacteria Prochlorococcus. Front Mar Sci. 2020;7. https://doi.org/ 10.3389/fmars.2020.571929.

36. Walter A, Gutknecht J. Monocarboxylic acid permeation through lipid bilayer membranes. J Membr Biol. 1984;77(3):255-64. https://doi.org/10.1007/bf01870573.

37. Escher BI, Glauch L, Konig M, Mayer P, Schlichting R. Baseline toxicity and volatility cutoff in reporter gene assays used for highthroughput screening. Chem Res Toxicol. 2019;32(8):1646-55. https://doi.org/10.1021/acs.chemrestox.9b00182.

38. Cid A, Fidalgo P, Herrero C, Abalde J. Toxic action of copper on the membrane system of a marine diatom measured by flow cytometry. Cytometry. 1996;25(1):32-6. https://doi.org/10.1002/(SICI) 1097-0320(19960901)25:1\%3c32::AID-CYTO4\%3e3.0.CO;2-G.

39. Kellogg EW, Fridovich I. Superoxide, hydrogen peroxide, and singlet oxygen in lipid peroxidation by a xanthine oxidase system. $\mathbf{J}$ Biol Chem. 1975;250(22):8812-7. https://doi.org/10.1016/s00219258(19)40745-x.

40. Goldstein IM, Weissmann G. Effects of the generation of superoxide anion on permeability of liposomes. Biochem Biophys Res Commun. 1977;75(3):604-9. https://doi.org/10.1016/0006291X(77)91515-7.

41. Niehaus WG. A proposed role of superoxide anion as a biological nucleophile in the deesterification of phospholipids. Bioorg Chem. 1978;7(1):77-84. https://doi.org/10.1016/0045-2068(78)90019-6.

42. Ghosh N, Das A, Chaffee S, Roy S, Sen CK (2018) Chapter 4 - Reactive oxygen species, oxidative damage and cell death. In: Chatterjee S, Jungraithmayr W, Bagchi D (eds) Immunity and Inflammation in Health and Disease. Academic Press, pp 45-55. https://doi.org/10.1016/B978-0-12-805417-8.00004-4

43. Escher BI, van Daele C, Dutt M, Tang JY, Altenburger R. Most oxidative stress response in water samples comes from unknown chemicals: the need for effect-based water quality trigger values. Environ Sci Technol. 2013;47(13):7002-11. https://doi.org/10. 1021/es304793h.

44. Brack W, Schmitt-Jansen M, Machala M, Brix R, Barcelo D, Schymanski E, Streck G, Schulze T. How to confirm identified toxicants in effect-directed analysis. Anal Bioanal Chem. 2008;390(8):195973. https://doi.org/10.1007/s00216-007-1808-8.

45. Schönlau C, Larsson M, Dubocq F, Rotander A, van der Zande R, Engwall M, Kärrman A. Effect-directed analysis of Ah receptormediated potencies in microplastics deployed in a remote tropical marine environment. Front Environ Sci. 2019;7. https://doi.org/10. 3389/fenvs.2019.00120.

Publisher's Note Springer Nature remains neutral with regard to jurisdictional claims in published maps and institutional affiliations. 


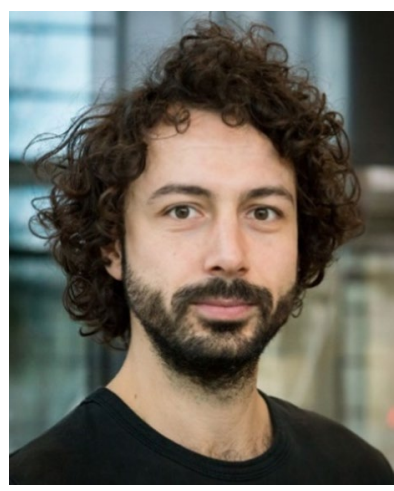

Christoph D. Rummel UFZ, holds a $\mathrm{PhD}$ in Environmental Science and his research focuses on chemical and ecotoxicological effects of weathering plastics in the environment. He is interested in the relevance of microplastics for chemical partitioning of organic contaminants and the risks posed by environmental plastics and their degradation products across different trophic levels.

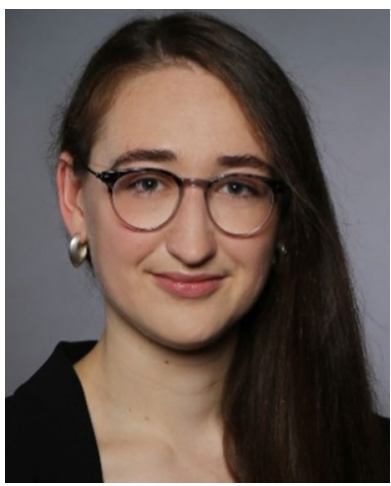

Hannah Schäfer formerly UFZ, has a university background in biology and toxicology. At UFZ, she worked on projects related to the toxicological assessment of plastic leachates, the distribution of contaminants in plastics, and effect-based monitoring of pesticides in agricultural streams. Currently, she holds a position at the LUBW, Germany, for environmental monitoring across media and focuses on ecotoxicological studies to assess the effects of pollutants in the environment.

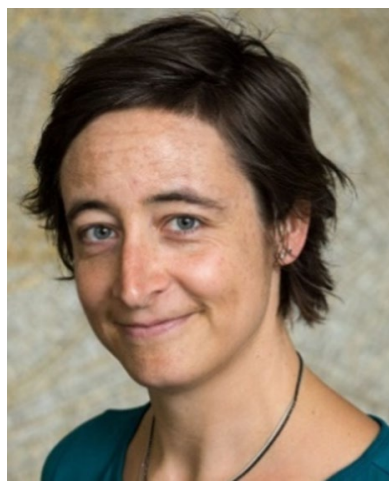

Annika Jahnke UFZ, pursues combining environmental and human health assessment using identical tools. She holds a $\mathrm{PhD}$ in Environmental Chemistry (2007) and a Professorship at RWTH Aachen University (since 2020). Her special interests are in environmental weathering of plastics and in novel passive equilibrium sampling to investigate chemical activity driving the partitioning, fate, and effects of environmental pollutants. Research ID: http://www.researcherid.com/ $\mathrm{rid} / \mathrm{D}-4528-2013$

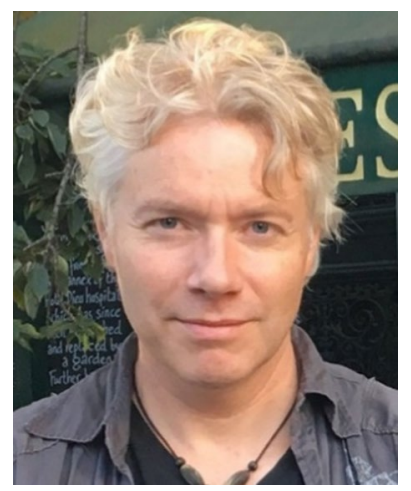

Hans Peter H. Arp NGI/NTNU, is an environmental chemist interested in how fundamental aspects of physical chemistry can best serve as applied tools for understanding exposure and preventing pollution in the environment. He holds a $\mathrm{PhD}$ from ETH Zürich (2008) and a Professorship at the Norwegian University of Science and Technology (since 2018). Research ID: https:// publons.com/researcher/2853969/ hans-peter-h-arp

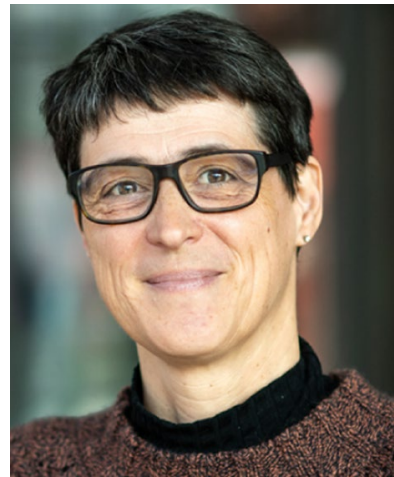

Mechthild Schmitt-Jansen UFZ, has a background in hydrobiology and is interested in the effects of chemical and non-chemical stressors on microbial organisms including emerging stressors like environmental plastics. She holds a $\mathrm{PhD}$ in Biology and focuses in her work on a mechanistic understanding of interacting stressor effects across biological scales using single species testing up to community assays and ecosystem level assessments. 